\title{
GMR
}

\section{Correlation analysis of serum obestatin expression with insulin resistance in childhood obesity}

\author{
M.Y. Zhang*, F. Li* and J.P. Wang \\ Department of Pediatrics, Shaoxing Second Hospital, Shaoxing, Zhejiang, China \\ *These authors contributed equally to this study. \\ Corresponding author: J.P. Wang \\ E-mail: jupingwangd@sina.com
}

Genet. Mol. Res. 16 (2): gmr16029210

Received September 8, 2016

Accepted December 12, 2016

Published April 28, 2017

DOI http://dx.doi.org/10.4238/gmr16029210

Copyright $(2017$ The Authors. This is an open-access article distributed under the terms of the Creative Commons Attribution ShareAlike (CC BY-SA) 4.0 License.

\begin{abstract}
Childhood obesity is a serious public health concern condition, as excess body fat can negatively affect a child's health. Obestatin is a hormone that regulates body weight by suppressing appetite and reducing food intake; fasting obestatin level is negatively correlated with basal insulin level. This study aims to investigate the role of obestatin in insulin resistance. A total of 54 children with simple obesity and 57 healthy controls were recruited. Levels of serum insulin, fasting blood glucose, cholesterol, triglyceride, low-density lipoprotein, and high-density lipoprotein were measured. Serum obestatin level was determined using an enzyme-linked immunosorbent assay. We found that body mass index and waist-hip ratio of obese children were significantly higher, while obestatin level in the obese group was significantly lower $(\mathrm{P}<0.001)$, as compared to those of controls. In addition, obese children exhibited higher levels of insulin, total cholesterol, triglyceride, and low-density lipoprotein $(\mathrm{P}<0.05)$ as compared to the controls. Fasting blood glucose and high-density lipoprotein levels were similar between the two groups $(\mathrm{P}>0.05)$. Leptin level in the obese group was also higher $(\mathrm{P}<0.05)$ as compared to that of control group. Results showed that insulin resistance index
\end{abstract}

Genetics and Molecular Research 16 (2): gmr16029210 
was positively correlated with body mass index, waist-hip ratio $(\mathrm{r}=$ $0.41, \mathrm{P}<0.001 ; \mathrm{r}=0.245, \mathrm{P}<0.001)$, and triglyceride level $(\mathrm{r}=0.25, \mathrm{P}$ $=0.04$ ). Our study demonstrated that obestatin is negatively correlated with fasting insulin and leptin levels, and positively correlated with insulin resistance in obese children.

Key words: Childhood obesity; Obestatin; Insulin resistance; Correlation

\section{INTRODUCTION}

Childhood obesity is a chronic nutritional disorder, and is fast becoming a global public health problem. Modern social living standards and lifestyle changes leads to rising obesity rates, especially in urban areas. Obesity is associated with various genetic and environmental factors, such as excessive food intake, and sedentary lifestyles. Obese children not only have numerous psychological barriers, but are also more susceptible to various metabolic diseases, hypertension, and diabetes ( $\mathrm{Su}$ et al., 2014). Obestatin is a hormone that is present in stomach tissues and circulation. Studies have shown that obestatin injections can affect food intake, prolong gastric emptying time, and reduce intestinal contraction frequency. Obestatin levels were reported to be reduced in obese individuals and were negatively correlated with body mass index (BMI) (Zou et al., 2009; Zhang et al., 2011). On the other hand, Holst et al. (2007) demonstrated that obestatin may affect food absorption in rats regardless of feelings of hunger . It has been postulated that obestatin can affect feeding behaviors and digestion by influencing pancreas and stomach ghrelin secretion (Chanoine et al., 2006).

Insulin resistance (IR) is defined as insensitivity of insulin on target organs. Aside from genetic factors, multiple environmental factors can also lead to IR, including obesity, long-term hyperglycemia, and tall dissociate fatty acid hematic disease. Research has shown that fat accumulation is correlated with IR and other metabolic diseases.

However, the relationship between obestatin and IR in obese children is still not well characterized. Therefore, the aim of the present study was to investigate the role of obestatin in IR by measuring serum obestatin level and IR in obese children.

\section{MATERIAL AND METHODS}

\section{Study subjects}

A total of 54 children with simple obesity were recruited between May 2015 and April 2016 in Shaoxing Second Hospital. Subjects included 31 males and 23 females, ranging between 5-14 years of age. All subjects received abdominal ultrasound and endocrine function tests to exclude other endocrine diseases, genetic diseases, and nervous system induced secondary obesity. Obesity was diagnosed via criteria published by Li et al. (2010), which defined BMI cut off points for 2-18-year-old children in China. Another 57 healthy children (33 males and 24 females) receiving physical examinations at the same hospital were selected as controls, and ranged between 5-14 years of age. Gender, age, height, weight, blood pressure, waistline, and hipline were recorded.

$$
\text { Body mass index }(\mathrm{BMI})=\text { weight }(\mathrm{kg}) / \text { height }^{2}\left(\mathrm{~m}^{2}\right)
$$

Genetics and Molecular Research 16 (2): gmr16029210 


$$
\text { Waist-hip ratio }(\text { WHR })=\text { waistline }(\mathrm{cm}) / \text { hipline }(\mathrm{cm}) \quad \text { (Equation } 2)
$$

The study protocol was approved by the Research Ethics Committee of Shaoxing Second Hospital, and informed consents were obtained from parents/guardians of all enrolled subjects.

\section{Blood sample collection and laboratory detection}

Peripheral venous blood (5 mL) was drawn following an 8-hour (at least) fast. Serum insulin (FINS), fasting blood glucose (FBG), as well as lipid profiles, including cholesterol (TC), triglyceride (TG), low density lipoprotein cholesterol (LDL-C), and high density protein of cholesterol (HDL-C) were measured, as previous described (Li et al., 2012). The homeostatic model assessment for insulin resistance (HOMA-IR) was used as a measure of insulin resistance.

$$
\mathrm{IR}=\mathrm{FINS} \times \mathrm{FBG} / 22.5
$$

Serum obestatin level was determined by enzyme-linked immunosorbent assay (ELISA).

\section{Statistical analysis}

Data analysis was carried out with the SPSS16.0 software. Measurement data are reported as means \pm standard deviation (SD), and were subjected to the Student's $t$-test or the rank-sum test. Enumeration data were tested by the chi-square test with the inspection level $\alpha$ $=0.05$. $\mathrm{P}$ value $<0.05$ was considered to be statistically significant.

\section{RESULTS}

\section{Gender, age, BMI, and WHR comparison}

No statistical differences in gender and age were observed between the obese and control groups. However, obese children presented significantly higher BMI, waist-to-hip ratio (WHR), and lower obestatin level as compared to those of controls $(\mathrm{P}<0.001)$ (Table 1).

Table 1. Gender, age, body mass index (BMI), and waist-to-hip ratio (WHR) of obese and control children.

\begin{tabular}{l|c|c|c}
\hline Index & Obese group & Controls & P value \\
\hline Male/female & $31 / 23$ & $33 / 24$ & 0.96 \\
\hline Age $($ year) & $9.03 \pm 4.23$ & $8.92 \pm 3.24$ & 0.88 \\
\hline BMI $\left(\mathrm{kg} / \mathrm{m}^{2}\right)$ & $25.02 \pm 4.21$ & $17.21 \pm 3.21$ & $\mathrm{P}<0.001$ \\
\hline WHR & $0.95 \pm 0.13$ & $0.84 \pm 0.09$ & $\mathrm{P}<0.001$ \\
\hline Obestatin level $(\mathrm{ng} / \mathrm{L})$ & $401.25 \pm 120.14$ & $495.34 \pm 90.35$ & $\mathrm{P}<0.001$ \\
\hline
\end{tabular}

\section{Biochemical criterion comparison}

Serum levels of FINS, FBG, TC, TG, LDLC, and HDLC were measured in all individuals. Results showed that insulin level in the obese group $(118.24 \pm 47.21)$ was significantly higher as compared to that in the control group $(57.67 \pm 50.65)(\mathrm{P}<0.05)$. However, FBG levels were similar between the two groups $(\mathrm{P}>0.05)$. Leptin (Ln) (IR) level

Genetics and Molecular Research 16 (2): gmr16029210 
was higher in the obese group as compared with that in the controls $(\mathrm{P}<0.05)$. In addition, the obese group demonstrated markedly higher TC, TG, and LDL-C levels $(\mathrm{P}<0.05)$ as compared to those in controls; HDL-C levels were comparable between the two groups (Figure 1).
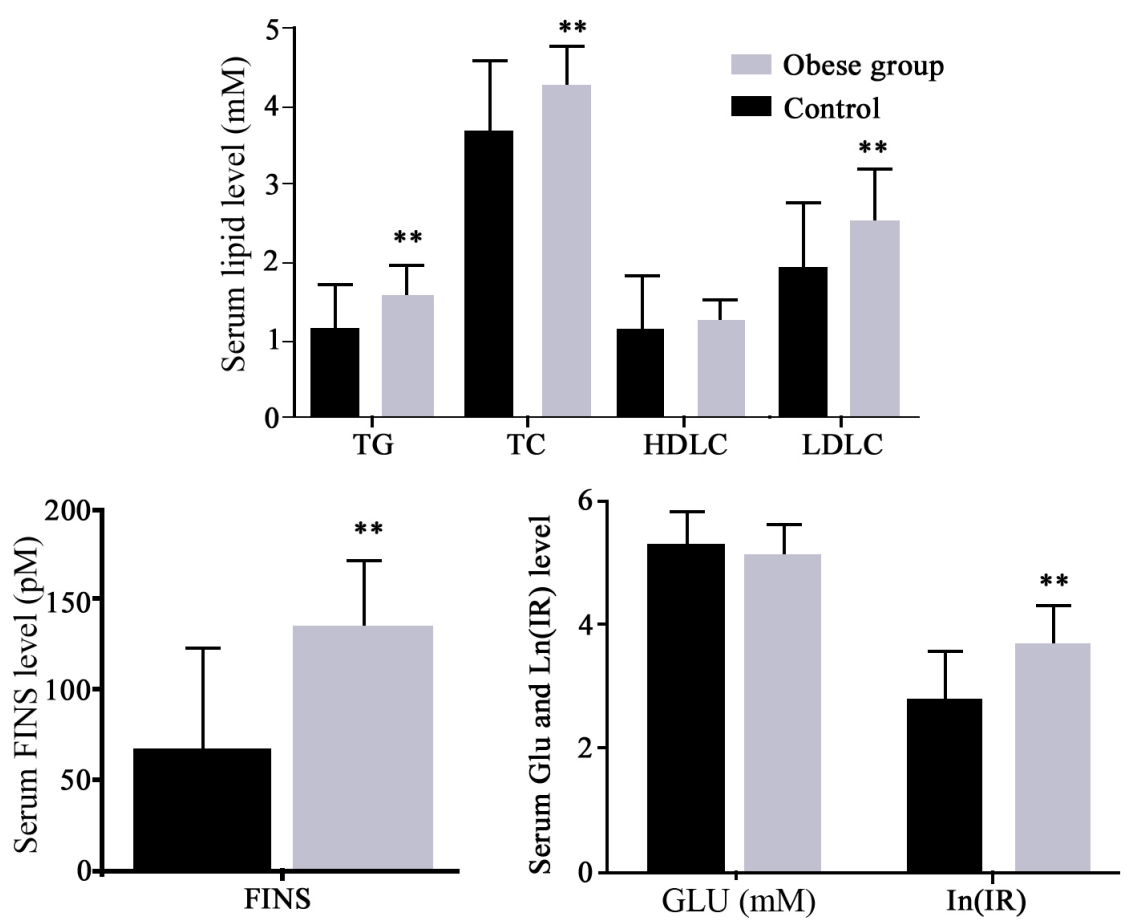

Figure 1. Biochemical criterion comparison. ${ }^{*} \mathrm{P}<0.05$ as compared with controls.

\section{Correlation analysis of HOMA-IR and blood lipid}

Correlation analysis was performed on HOMA-IR with BMI, WHR, and blood lipid indexes. We found that HOMA-IR was positively correlated with BMI, WHR, and serum TG $(\mathrm{P}<0.05)$, suggesting that BMI, WHR, and TG may be involved in the development and pathogenesis of IR (Table 2).

Table 2. Correlation analysis of HOMA-IR with BMI, WHR, and blood lipid.

\begin{tabular}{l|c|c|c|c|c|c}
\hline Index & $\begin{array}{c}\text { BMI } \\
\text { (body mass index) }\end{array}$ & $\begin{array}{c}\text { WHR } \\
\text { (waist-to-hip ratio) }\end{array}$ & $\begin{array}{c}\text { TC } \\
\text { (cholesterol) }\end{array}$ & $\begin{array}{c}\text { TG } \\
\text { (triglyceride) }\end{array}$ & $\begin{array}{c}\text { LDLC } \\
\text { (low density lipoprotein cholesterol) }\end{array}$ & $\begin{array}{c}\text { HDLC } \\
\text { (high density protein of cholesterol) }\end{array}$ \\
\hline $\mathrm{r}$ value & 0.41 & 0.245 & 0.10 & 0.25 & 0.07 & 0.12 \\
\hline $\mathrm{P}$ value & $\mathrm{P}<0.001$ & $\mathrm{P}<0.001$ & 0.23 & 0.04 & 0.65 & 0.15 \\
\hline
\end{tabular}

\section{Correlation analysis of obestatin}

Correlation analysis demonstrated that obestatin was negatively correlated with BMI and Ln (IR), but not WHR and other blood lipid indexes (Table 3).

Genetics and Molecular Research 16 (2): gmr16029210 
Table 3. Correlation analysis of obestatin.

\begin{tabular}{|c|c|c|c|c|c|c|c|c|}
\hline Index & $\begin{array}{c}\text { BMI } \\
\text { (body yassindex) }\end{array}$ & $\begin{array}{l}\text { WHR } \\
\text { (waist-o-hip ratio) }\end{array}$ & $\begin{array}{ll}\operatorname{Ln}(\mathrm{IR}) \\
\end{array}$ & $\begin{array}{c}\text { FINS } \\
\text { (Serum insulin) }\end{array}$ & \begin{tabular}{|l|l} 
TC \\
(cholesterol) \\
\end{tabular} & $\begin{array}{c}\mathrm{TG} \\
\mathrm{TG}\end{array}$ & $\begin{array}{c}\text { LDL-C } \\
\text { (low density lipoprotein cholesterol) }\end{array}$ & 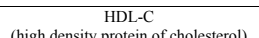 \\
\hline & $\begin{array}{l}\text { (body mass index) } \\
-0.215\end{array}$ & (Waist-10-hip ratio) & $\frac{(\text { Lepdin) }}{-0.223}$ & $\begin{array}{l}\text { (Serum insulin) } \\
-0.345\end{array}$ & $\begin{array}{l}\text { (cholesterol) } \\
0.058\end{array}$ & $\begin{array}{l}\text { (triglycride) } \\
0.067\end{array}$ & (low density lipopopotein cholesterol) & \begin{tabular}{|l} 
(high density protein of \\
0.065
\end{tabular} \\
\hline $\begin{array}{l}\text { P value } \\
\text { s. }\end{array}$ & $\mathrm{P}<0.001$ & 0.45 & $\mathrm{P}<0.001$ & $\mathrm{P}<0.001$ & 0.24 & 0.45 & 0.42 & 0.29 \\
\hline
\end{tabular}

\section{DISCUSSION}

The main reason for simple obesity in children is energy metabolism imbalance. Adipose accumulation often causes abnormal metabolic processes, and can lead to metabolic syndromes. Obesity arises due to elevated fatty acid levels, leading to excess lipid accumulation and activation of inflammatory pathways, which results in IR (Makki et al., 2013). Previous studies showed that obesity could easily lead to free fatty acid deposition in storage organs such as the liver and muscle tissues. Abnormal fat deposition is one of the main factors for pathogenesis of IR (Consitt et al., 2009; Samuel, 2011). Therefore, IR often occurs in obese people. Our results confirmed that HOMA-IR was positively correlated with BMI, which was consistent with a previous report by Barseem and Helwa (2015). Furthermore, our results demonstrated that obese children were prone to blood lipid disorders, as they showed significantly higher serum TC, TG, and LDL-C levels as compared with controls.

Obestatin is an active peptide with multiple biological functions, such as stimulating cell proliferation, differentiation, and sugar and lipid metabolism (Gesmundo et al., 2013). Obestatin can prevent IR occurrence by influencing insulin secretion. Ghrelin and obestatin, two gastrointestinal peptides formed via post-translational processing of the common precursor-preproghrelin, play important physiological roles in obesity and hypertension (Wang et al., 2014). Our results showed that peripheral obestatin level in obese children was significantly lower than that of normal controls, and was negatively correlated with BMI, which was consistent with previous reports by Shen et al. (2013). Obestatin declination in obese patients leads to decreased suppression of appetite and subsequent weight gain (Arslan et al., 2010). TG reduction was also found to be associated with obestatin levels (Agnew et al., 2011). While most studies suggest that obestatin is negatively correlated with IR, the specific mechanisms driving this phenomenon is still unclear. It is thought that obestatin can regulate $\beta$ cells and expression of insulin related genes, thus affecting insulin secretion and sensitivity.

Various studies have suggested that that BMI and basal insulin is negatively correlated with fasting obestatin levels (Lippl et al., 2008; Wali et al., 2014); TG and TC are also associated with IR. IR leads to down-regulation of esterase synthesis and activity, resulting in reduced TG hydrolysis and overall elevation of TG. Our study showed that IR leads to changes in BMI, WHR, and TG levels, suggesting that these factors may be reliable markers for predicting the occurrence and development of IR. In obese children, obestatin showed negative correlation with Ln (IR) and FINS, which was consistent with previous reports (Nakahara et al., 2008). Obestatin injections in Wistar rats can significantly reduce the occurrence of pancreatic edema (Ceranowicz et al., 2009). Obestatin can also treat cerulein-induced acute pancreatitis (Bukowczan et al., 2016). Interestingly, obstatin and insulin show interdependent relationship; insulin can reduce obestatin level in insulin sensitive patients (Anderwald-Stadler et al., 2007), suggesting that insulin and insulin sensitivity are important factors affecting obestatin secretion. Similarly, metabolic abnormalities resulting in altered insulin secretion may affect obestatin levels as well (Huang et al., 2012).

Genetics and Molecular Research 16 (2): gmr16029210 
However, the exact mechanisms driving the correlation between obestatin and IR in obese children are not fully understood. Whether the correlation between obestatin and IR solely occur in simple obesity or other metabolic disorders, and whether this relationship holds true in the adult population remain to be investigated.

To conclude, weight control in children is a serious public health concern, and can result in IR, which is associated with multiple cardiovascular and cerebrovascular diseases. Obestatin plays an important role in childhood obesity, and may participate in IR. However, further investigation is required to determine the exact mechanism by which obestatin regulates insulin.

\section{Conflicts of interest}

The authors declare no conflict of interest.

\section{ACKNOWLEDGMENTS}

We thank the anonymous reviewers for reviewing this manuscript.

\section{REFERENCES}

Agnew A, Calderwood D, Chevallier OP, Greer B, et al. (2011). Chronic treatment with a stable obestatin analog significantly alters plasma triglyceride levels but fails to influence food intake; fluid intake; body weight; or body composition in rats. Peptides 32: 755-762. http://dx.doi.org/10.1016/j.peptides.2010.12.005

Anderwald-Stadler M, Krebs M, Promintzer M, Mandl M, et al. (2007). Plasma obestatin is lower at fasting and not suppressed by insulin in insulin-resistant humans. Am. J. Physiol. Endocrinol. Metab. 293: E1393-E1398. http:// dx.doi.org/10.1152/ajpendo.00330.2007

Arslan N, Erdur B and Aydin A (2010). Hormones and cytokines in childhood obesity. Indian Pediatr. 47: 829-839. http:// dx.doi.org/10.1007/s13312-010-0142-y

Barseem NF and Helwa MA (2015). Homeostatic model assessment of insulin resistance as a predictor of metabolic syndrome: Consequences of obesity in children and adolescents. Egypt. Pediatr. Assoc. Gaz. 63: 19-24. http://dx.doi. org/10.1016/j.epag.2014.12.001

Bukowczan J, Cieszkowski J, Warzecha Z, Ceranowicz P, et al. (2016). Therapeutic effect of obestatin in the course of cerulein-induced acute pancreatitis. Pancreas 45: 700-706. http://dx.doi.org/10.1097/MPA.0000000000000517

Ceranowicz P, Warzecha Z, Dembinski A, Cieszkowski J, et al. (2009). Pretreatment with obestatin inhibits the development of cerulein-induced pancreatitis. J. Physiol. Pharmacol. 60: 95-101.

Chanoine JP, Wong AC and Barrios V (2006). Obestatin, acylated and total ghrelin concentrations in the perinatal rat pancreas. Horm. Res. 66: 81-88.

Consitt LA, Bell JA and Houmard JA (2009). Intramuscular lipid metabolism, insulin action, and obesity. IUBMB Life 61: 47-55. http://dx.doi.org/10.1002/iub.142

Gesmundo I, Gallo D, Favaro E, Ghigo E, et al. (2013). Obestatin: a new metabolic player in the pancreas and white adipose tissue. IUBMB Life 65: 976-982. http://dx.doi.org/10.1002/iub.1226

Holst B, Egerod KL, Schild E, Vickers SP, et al. (2007). GPR39 signaling is stimulated by zinc ions but not by obestatin. Endocrinology 148: 13-20. http://dx.doi.org/10.1210/en.2006-0933

Huang J, Zhang Y, Yu S, Gan X, et al. (2012). Circulating obestatin concentration is lowered by insulin in rats. Exp. Clin. Endocrinol. Diabetes 120: 56-58. http://dx.doi.org/10.1055/s-0031-1284430

Li H, Zong XN, Ji CY and Mi J (2010). Body mass index cut-offs for overweight and obesity in Chinese children and adolescents aged 2 - 18 years. Zhonghua Liu Xing Bing Xue Za Zhi 31: 616-620.

Li Y, Chen M, Xuan H and Hu F (2012). Effects of encapsulated propolis on blood glycemic control, lipid metabolism, and insulin resistance in type 2 diabetes mellitus rats. Evid. Based Complement. Alternat. Med. 2012: 981896. http:// dx.doi.org/10.1155/2012/981896

Lippl F, Erdmann J, Lichter N, Tholl S, et al. (2008). Relation of plasma obestatin levels to bmi, gender, age and insulin. Horm. Metab. Res. 40: 806-812. http://dx.doi.org/10.1055/s-2008-1081503

Genetics and Molecular Research 16 (2): gmr16029210 
Makki K, Froguel P and Wolowczuk I (2013). Adipose tissue in obesity-related inflammation and insulin resistance: cells, cytokines, and chemokines. ISRN Inflamm. 2013: 139239. http://dx.doi.org/10.1155/2013/139239

Nakahara T, Harada T, Yasuhara D, Shimada N, et al. (2008). Plasma obestatin concentrations are negatively correlated with body mass index, insulin resistance index, and plasma leptin concentrations in obesity and anorexia nervosa. Biol. Psychiatry 64: 252-255. http://dx.doi.org/10.1016/j.biopsych.2007.08.005

Samuel VT (2011). Fructose induced lipogenesis: from sugar to fat to insulin resistance. Trends Endocrinol. Metab. 22: 60-65. http://dx.doi.org/10.1016/j.tem.2010.10.003

Shen C, Yu T, Tang ZH and Wu KM (2013). Changes in ghrelin and obestatin levels before and after a meal in children with simple obesity and anorexia. Horm. Res. Paediatr. 79: 341-346. http://dx.doi.org/10.1159/000351464

Su XJ, Dong RX, Li YP, Yang SG, et al. (2014). Obestatin and cardiovascular health. Peptides 52: 58-60. http://dx.doi. org/10.1016/j.peptides.2013.11.023

Wali P, King J, He Z, Tonb D, et al. (2014). Ghrelin and obestatin levels in children with failure to thrive and obesity. $J$. Pediatr. Gastroenterol. Nutr. 58: 376-381. http://dx.doi.org/10.1097/MPG.0000000000000223

Wang WM, Li SM, Du FM, Zhu ZC, et al. (2014). Ghrelin and obestatin levels in hypertensive obese patients. J. Int. Med. Res. 42: 1202-1208. http://dx.doi.org/10.1177/0300060514543040

Zhang N, Yuan C, Li Z, Li J, et al. (2011). Meta-analysis of the relationship between obestatin and ghrelin levels and the ghrelin/obestatin ratio with respect to obesity. Am. J. Med. Sci. 341: 48-55. http://dx.doi.org/10.1097/ MAJ.0b013e3181ec41ed

Zou CC, Liang L, Wang CL, Fu JF, et al. (2009). The change in ghrelin and obestatin levels in obese children after weight reduction. Acta Paediatr. 98: 159-165. http://dx.doi.org/10.1111/j.1651-2227.2008.00997.x

Genetics and Molecular Research 16 (2): gmr16029210 